\title{
Self-medicated, satranidazole induced fixed drug eruption: a case report
}

\author{
Divyashanthi Chellathambi Malathi*, Anusha Bommasani, Raman Palanisami Priyadharsini
}

Department of Pharmacology, Jawaharlal Institute of Postgraduate Medical Education and Research, Karaikal, Puducherry, India

Received: 23 September 2020

Accepted: 29 October 2020

\section{*Correspondence:}

Dr. Divyashanthi Chellathambi Malathi,

Email: dishanthii@gmail.com

Copyright: (c) the author(s), publisher and licensee Medip Academy. This is an open-access article distributed under the terms of the Creative Commons Attribution Non-Commercial License, which permits unrestricted non-commercial use, distribution, and reproduction in any medium, provided the original work is properly cited.

\begin{abstract}
Fixed drug eruption (FDE) is described as the development of one or more annular or oval erythematous patches as a result of systemic exposure to a drug; these reactions normally resolve with hyperpigmentation and may recur at the same site with re-exposure to the drug. Repeated exposure to the offending drug may cause new lesions to develop in addition to lighting up the older hyperpigmented lesions. Here we present an interesting case of satranidazole induced FDE with a past history of FDE to the same drug 5 months back. Since the eruption occurred in the same site on reexposure to the same drug, a diagnosis of FDE was made and causality assessment by Naranjo adverse drug reaction probability scale showed a certain relationship between the cutaneous adverse reaction and the offending drug
\end{abstract}

Keywords: Fixed drug eruption, Satranidazole, Self-medication

\section{INTRODUCTION}

Cutaneous drug reactions are the most frequently occurring adverse reactions to drugs. The frequency of cutaneous reactions to specific drugs may exceed $10 \%$. There are four categories of cutaneous drug reactions: immediate-type immune-mediated reactions, delayedtype immune-mediated reactions, photosensitivity reactions, and autoimmune syndromes. ${ }^{1}$ Drug induced cutaneous eruptions frequently display a characteristic clinical morphology such as morbilliform exanthem, urticaria, hypersensitivity syndrome pseudolymphoma, photosensitivity, pigmentary changes, acute generalized exanthematous pustulosis, lichenoid dermatitis, vasculitis, Steven-Johnson syndrome, or fixed drug eruption. $^{2}$

Fixed drug eruption (FDE) are distinct type of drug eruptions that appear as pruritic, well circumscribed, round or oval-shaped, erythematous macules or edematous plaques and characteristically recur at the same sites up on re exposure to the offending drug. They usually resolve spontaneously with hyperpigmentation. ${ }^{3}$ After healing, lesions present on the skin and mucous membrane for prolonged periods as grey brown macules. On repeated exposure the number and severity of lesions may increase. Symptoms like swelling and redness of skin can be seen as early within 30 minutes of exposure to the drug. Extremities, genitals and perianal areas are the most common areas where the lesions can be seen but they may appear on any location.

Nitroimidazoles are low molecular weight antimicrobial compounds with excellent activity against anaerobic micro-organisms and protozoa. They are the first line drugs for hepatic and intestinal amoebiasis. All the nitroimidazoles: metronidazole, tinidazole, ornidazole, secnidazole and satranidazole, have a similar nitroimidazole ring but different side chains.

Although all these molecules have been used for a long time without many side-effects, only metronidazole and 
tinidazole have been reported to cause FDEs with cross sensitivity to each other and are included in the list of drugs causing FDE. ${ }^{4,5}$ To our knowledge so far, no reports for satranidazole had been reported. We thought it is an interesting case of satranidazole induced FDE that happened during the COVID-19 pandemic.

\section{CASE REPORT}

A 30-year-old woman who had diarrheal episodes with mild abdominal pain approximately 5 months back, selfmedicated herself with tablets which her relative had been prescribed by a general practitioner for similar complaints. After a few hours she had experienced mild itching over the right side of her lower lip which increased in intensity. She convinced herself that it could be due to some insect bite and did some home remedies. She has taken only two tablets from that strip and discontinued treatment as her gastrointestinal symptoms improved. But the lesion over the lip remained with a hyperpigmentation for nearly 10 days after which it gradually disappeared (Figure 1).

Again after 5 months, as the woman had loose stools after eating outside food, she took the same tablet from the left-over strip and within 4 hours she developed intense itching over the right side of her lower lip exactly in the same site that she had developed for the first time. This time as the lesion was painful and itchy, she consulted a physician and was diagnosed as a FDE and the offending drug was stopped immediately and she was treated with topical vaseline gel and systemic antihistamines after which the symptoms subsided. On day 2 the lesion became dry and less itchy. The third day the lesion became dry with a scab formed over it. Itching and redness got relieved gradually.

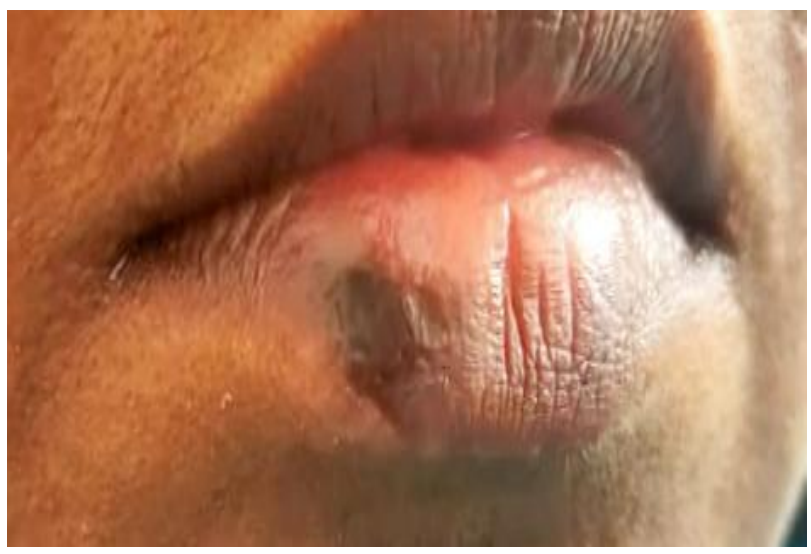

Figure 1: Day 3 of FDE, after stopping the drug and started treatment with antihistamines.

\section{DISCUSSION}

Self-medication has been defined as the use of drugs to treat self-diagnosed disorders or symptoms or the intermittent, or continued use of prescribed drugs for chronic or recurrent disease or symptoms. ${ }^{6}$ Here our patient has approached for treatment only when she had the FDE for the second time, which otherwise could have been missed.

Satranidazole an antimicrobial agent, belongs to a group of nitroimidazoles, has broad spectrum cidal activity against protozoa and some anaerobic bacteria. It is well absorbed orally and widely distributed and has a half-life of 14 hours. Though satranidazole has similar potency with that of metronidazole it differs in adverse effect profile as it is devoid of producing metallic taste (notorious with metronidazole) neurological adverse effects and disulfiram like reaction. Because of these advantages the drug could have been prescribed for the patients relative who is an alcoholic for whom the compliance was very good.

Though many cases of FDE induced by other nitroimidazoles have been reported so far, no such reaction with satranidazole has been reported. Here in this patient, temporal association between the drug and the reaction, de-challenges and rechallenge are positive and we have graded this as a certain type of adverse drug reaction according to Naranjo's scale.

\section{CONCLUSION}

Though FDR could be produced by a wide variety of drugs, during this unprecedented COVID-19 times, increased self-medication with drugs especially with over the counter (OTC) antibiotics could not only increase the chances of drug resistance but also increase the cost of treating drug induced diseases. Public awareness about adverse drug reactions and its prompt reporting, the cost to be incurred in managing those and the problem of developing antimicrobial resistance should be created through public forums and other media. Thus, improved knowledge about self-medication would possibly mitigate the adverse drug reactions and improve its management.

Funding: No funding sources

Conflict of interest: None declared

Ethical approval: Not required

\section{REFERENCES}

1. Svensson CK, Cowen EW, Anthony A. Cutaneous drug reactions. Pharmacol Rev. 2001;53(3):357-79.

2. Butler DF. Fixed Drug Eruptions Clinical Presentation. Medspace. Dermatol. 2020.

3. Shiohara T. Fixed drug eruption: pathogenesis and diagnostic tests. Curr Opin Allergy Clin Immunol. 2009;9(4):316-21.

4. Kanwar AJ, Sharma R, Rajgopalan M, Kaur S. Fixed drug eruption due to tinidazole with cross sensitivity to metronidazole. Dermatologica. 1990;180(4):277.

5. Thami GP, Kanwar AJ. Fixed drug eruption due to metronidazole and tinidazole without cross- 
sensitivity to secnidazole. Dermatol. 1998;196(3):368.

Cite this article as: Malathi DC, Bommasani A, Priyadharsini RP. Self-medicated, satranidazole induced fixed drug eruption: a case report. Int $\mathrm{J}$ Basic Clin Pharmacol 2020;9:1903-5. 